\title{
Pharmacokinetics of intravenous and oral metformin and R, S-verapamil in Sinclair, Hanford, Yucatan and Göttingen minipigs
}

\begin{abstract}
Aim: Oral and intravenous pharmacokinetic (PK) studies were conducted in four different minipig strains: Sinclair, Yucatan, Hanford and Göttingen after administration of metformin or R, S-verapamil (R,S-VER). Results: The results indicated that the PK of metformin was similar between all minipig strains, except for the Göttingen which had higher plasma clearance. The plasma clearance of both $(+)-(R)$ - and (-)-(S)VER was significantly lower in Sinclair compared with the clearance in other strains. The $(+)-(R)$-NOR to R,S-VER ratio was significantly higher in the Sinclair. There was a preferential conversion of R, S-VER to $(+)-(R)$-NOR over $(-)-(S)$-NOR in all minipig strains. Conclusion: This work highlights the importance of considering the impact of metabolic and dispositional differences in minipig strains when conducting PK studies.
\end{abstract}

First draft submitted: 4 February 2016; Accepted for publication: 13 July 2016; Published online: 9 August 2016

Keywords: bioavailability $\bullet$ minipig strains $\bullet$ minipigs $\bullet$ pharmacokinetics

Pigs have become increasingly useful models in drug development in Europe and now in the USA due to their anatomical and functional similarities to humans with respect to their skin, GI and immune system. They are often considered as relevant disease models for arteriosclerosis, metabolic syndrome, gastric ulcer, wound healing as well as toxicology evaluations that support regulatory packages [1]. Compared with the domestic pig, the advantages of the minipig are its ease of handling because of its inherently smaller size, even at full maturity, which is particularly suitable for long-term studies [1]. Accordingly, minipigs such as Yucatan, Hanford, Sinclair and Göttingen have been widely used for chronic studies, lasting up to 9 months [1-3]. The use of minipig in biomedical research is enabled by the collection of larger volumes of multiple samples of body fluids and biopsies compared with rodents, thus making it possible to conduct studies that approximate to those performed in humans. In dermatological studies, skin penetration and irritation is evaluated because properties of pig skin are deemed most similar to human skin. Several pig models have been established for studying drug effects in myocardial infarction and ischemia-induced acute kidney injury studies [4-6]. The pharmacokinetics (PK) of drugs in minipigs has been studied to assess formulation comparisons, as well as in support of toxicology evaluations. Oral dosing is one of the preferred routes of drug administration due to its convenience. Therefore, an appropriate model for studying oral drug delivery is necessary for drug discovery and development. A comparison of the range of $\mathrm{pH}$ values reported for different portions of the GI tract indicates most similarities between human and pig over mouse, rat, dog, rabbit or monkey [7]. Furthermore, the total small and large intestinal surface area as well as the small intestinal transit time for solids is most similar between human and pig, compared with mouse and $\operatorname{dog}[8]$. These similarities support the use of minipig over other species in the investigation of oral absorption profiles
Nita J Patel', Nathan Yumibe', Kenneth Ruterbories', Naijia Huang ${ }^{1}$, Lee Burns ${ }^{1}$, Jeffrey Tan', David White', Jason Liu $^{2}$, Derek Brocksmith ${ }^{3}$, Guy Bouchard ${ }^{2}$ \& Alain Stricker-Krongrad ${ }^{*}, 2$ 'Drug Disposition, Eli Lilly \& Company, Indianapolis, IN, USA

${ }^{2}$ Sinclair Research Center, LLC, 562 State Road Dd, Auxvasse, MO 65231, USA ${ }^{3}$ Sinclair Bio Resources, LLC, Auxvasse, MO, USA

*Author for correspondence: astricker@sinclairresearch.com

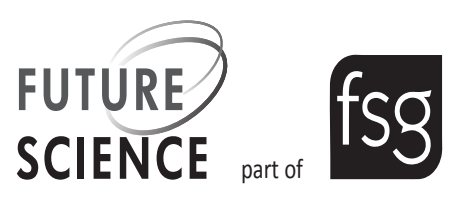


for drug discovery and development programs [9]. From a metabolism perspective, the results presented on the comparability of hepatic P450 cytochromes between pigs and humans support the usefulness of minipigs as experimental animals to predict biotransformation pathways in man [10-14]. Some evidence of strain differences have been observed, for example hepatic CYP3A4 activity in the Göttingen is greater than in conventional pigs with a slight gender difference in both strains $[10,12]$. While pharmacology or toxicology data may be collected in different strains of pigs with appropriate considerations, a clear indication on whether strain differences would affect PK properties of drug candidates is needed. To this point, differences in the PK of compounds such as paracetamol in the Göttingen minipig [15] and diclofenac in the Yucatan minipig [16] have been noted when compared with human, but it is unclear if these differences are specific to the minipig or just one of the strains.

We selected two molecules to evaluate PK differences in four lineages of minipig. Metformin (MET) is an antihyperglycemic agent commonly used for the treatment of Type II diabetes mellitus. In humans, MET is not metabolized and is cleared from the body by renal tubular secretion and excreted unchanged in the urine; MET is undetectable in blood plasma within $24 \mathrm{~h}$ of a single oral dose with a mean plasma elimination half-life after oral administration of between 4.0 and $8.7 \mathrm{~h} \mathrm{[17].} \mathrm{R,S-verapamil} \mathrm{(R,S-VER),} \mathrm{a} \mathrm{calcium}$ channel-blocker, is a chiral drug that is administered as a racemic mixture and is known to undergo an extensive enantioselective first-pass effect after oral administration [18]. R,S-VER undergoes extensive oxidative metabolism with formation of an active metabolite norverapamil (NOR) [19]. The bioavailability of $(-)-(S)$-VER is greater than that of $(+)-(R)$-VER and the clearance of $(+)-(R)$-VER is greater than that of $(-)-(S)$-VER after oral administration in rats. Furthermore, enantioselectivity in rat plasma is opposite to that observed in human plasma. Plasma protein binding studies have also revealed opposite enantioselectivity in the free fraction in rat $(R>S)$ and human $(S$ $>\mathrm{R}$ ) plasma for verapamil (VER) [20]. In this work, the PKs of MET that is primarily cleared by the renal route and R,S-VER that is highly metabolized and has enantiomeric differences in its disposition were studied to provide an initial basis of PK comparisons between four strains of minipigs.

\section{Materials \& methods}

\section{Materials}

MET HCL was purchased from MP Biomedicals, LCC $(\mathrm{OH}, \mathrm{USA})$ and its internal standard $\left(\left[{ }^{2} \mathrm{H}_{6}\right] \mathrm{MET}\right)$ was purchased from Toronto Research Chemicals Inc.
(Toronto, Canada). R,S-VER.HCL was purchased from Toronto Research Chemicals Inc.; its enantiomers $((+)-(R)-\mathrm{NOR} . \mathrm{HCl},(-)-(S)-\mathrm{NOR} . \mathrm{HCl},(+)-(R)-$ VER mono $\mathrm{HCl}$ hydrate, (-)-(S)-VER.HCl Hydrate) were purchased from Sigma-Aldrich (MO, USA). The internal standards (D7-VER and D7-NOR) were purchased from SynFine Research Inc (Richmond Hill, Canada). All chemical and reagents were purchased at the highest purity grade level, including United States Pharmacopeia grade. Hydroxyethylcellulose (HEC) suspension vehicle for oral dosing ( $1 \%$ hydroxyethylcellulose, $0.25 \%$ polysorbate $80,0.05 \%$ antifoam, water) and intravenous solution vehicle ( $20 \%$ hydroxypropyl-beta-cyclodextrin, phosphate buffer $\mathrm{pH} 2$ ) were prepared at Eli Lilly and stored at $-20^{\circ} \mathrm{C}$ [21].

\section{Animals}

This work was performed under a research and animal use protocol approved by the Sinclair Research Center, LLC Institutional Animal Care and Use Committee (MO, USA) and was conducted in an Association for Assessment and Accreditation of Laboratory Animal Care accredited facility in compliance with the Animal Welfare Act (Animal Welfare Act of 1966, Federal Register) and the Guide for the Care and Use of Laboratory Animals. All the four strains were bred in the continental US: the Sinclair, Yucatan, and Hanford animals were obtained from Sinclair BioReseources (MO, USA) and the Göttingen animals were obtained from Marshall Bioresources (NY, USA). The animals were under the care of a staff veterinarian at all times during the studies. Four male minipigs from each strain that were at least 3 months of age with an average body weight of approximately $15 \mathrm{~kg}$ for the Sinclair, Hanford and Yucatan strains and $11 \mathrm{~kg}$ for the Göttingen strain were selected for the studies (Table 1). Male animals were used in order to prevent the effects of different female sexual hormones cycles in different animals and their interference with the metabolism of xenobiotics. The animals were surgically castrated in order to prevent the presence of aggressive behavior directed toward congeners and to prevent the formation of armor plates in the scapular area that would interfere with the access ports. Dual vascular access ports were implanted in their jugular veins with subcutaneous access in the prescapular regions. Following surgical recovery, the animals were acclimated to dosing and bleeding with vehicle by the oral route. Animals received their standard food ration at $3 \mathrm{pm}$ each day while not on study. A certified minipig feed with a $4 \%$ fiber content was provided (Purina ${ }^{\circledR}$ Sinclair S9 from LabDiet, MO, USA). All study animals were food-fasted overnight prior to dosing and were fed on the regular evening schedule at $3 \mathrm{pm}$ (approximately 
Table 1. Age and weight-matched strains of minipig.

\begin{tabular}{lll}
\hline Strain & Age at first dose (months) & Body weight (kg) \\
Sinclair & $4.5 \pm 0.1$ & $14.8 \pm 2.1$ \\
\hline Yucatan & $4.2 \pm 0.2$ & $14.6 \pm 0.3$ \\
Hanford & $4.4 \pm 0.0$ & $14.3 \pm 1.2$ \\
\hline Göttingen & $4.7 \pm 0.3$ & $11.3 \pm 0.8$ \\
\hline
\end{tabular}

$6 \mathrm{~h}$ postdose). All study animals had ad libitum access to clean, fresh water throughout the dosing and blood collection period. Animals did not have access to rooting materials, such as chopped or long straw, in order to avoid any interference with the absorption of drugs. The animals were dosed orally with MET.HCL formulated in $1 \%$ hydroxyethylcellulose $(\mathrm{w} / \mathrm{v}), 0.25 \%$ polysorbate $80(\mathrm{v} / \mathrm{v}), 0.05 \%$ antifoam $(\mathrm{v} / \mathrm{v})$, purified water q.s. at a dose of $5 \mathrm{mg} / \mathrm{kg}$ in a $5 \mathrm{ml} / \mathrm{kg}$ dose volume [21]. After a 7-day washout period, the animals were intravenously administered $0.5 \mathrm{mg} / \mathrm{kg}$ of MET. HCL or R,S-VER formulated in $25 \mathrm{mM} \mathrm{NaPO}_{4}$ buffer, pH6 [21]. Blood samples were collected in $\mathrm{K}_{2}$ EDTA tubes prior to dosing and at selected time points up to $48 \mathrm{~h}$ after dose administration. Vials were placed on ice after collection, centrifuged at $4^{\circ} \mathrm{C}$ and then processed to separate plasma and stored frozen at $-80^{\circ} \mathrm{C}$ before LC/MS/MS analysis.

\section{Protein binding}

In vitro plasma protein binding was determined using the equilibrium dialysis method. The $150 \mu \mathrm{l}$ half-cell capacity equilibrium dialyzer was used to conduct the assay using cellulose membranes. The 96-well equilibrium dialysis cells were assembled using HTDialysis membranes (CT, USA) with molecular weight cut off ranging from 12,000 to $14,000 \mathrm{Da}$ that were conditioned as follows: soaked for at least $60 \mathrm{~min}$ in Milli-Q water, then overnight in $20 \%$ ethanol, followed by a rinse with Milli-Q water and then soaked $15 \mathrm{~min}$ in phosphate butter, $\mathrm{pH7.4.} \mathrm{(+)-(R)-VER} \mathrm{or} \mathrm{(-)-(S)-VER}$ $(270 \mu \mathrm{M}$ stock) were individually spiked into $996 \mu \mathrm{l}$ of plasma from human or various minipig strains. Samples were vortex mixed for 30-60 s and six initial concentration replicates were transferred into a 96-well plate $\left(\mathrm{C}_{\text {initial }}\right)$. Internal standard in acetonitrile was added to precipitate the matrix. Aliquots $(100 \mu \mathrm{l})$ of each spiked matrix sample were placed into the donor side and an equal volume of $100 \mathrm{mM}$ phosphate buffer, $\mathrm{pH} 7.4$ was placed into each corresponding receiver well. Dialysis was conducted at $120 \mathrm{rpm}$ in an orbital shaker at $37^{\circ} \mathrm{C}$ for $6 \mathrm{~h}$. All remaining spiked samples were placed in an incubator alongside the dialysis plate at the same temperature and for the same time. Following incubation, one aliquot from each donor well $\left(\mathrm{C}_{\text {donor }}\right)$ was placed into the 96 -well plate and precipi- tated with internal standard in acetonitrile. One aliquot from each of the receiver wells $\left(\mathrm{C}_{\text {reciever }}\right)$ was placed into the plate containing internal standard in acetonitrile and blank matrix alongside six replicates of the incubated spiked sample tubes $\left(\mathrm{C}_{\text {final }}\right)$ were placed into a 96-well plate with internal standard in acetonitrile. Samples were analyzed for $(+)-(R)-$ VER and $(-)-(S)$ VER concentrations using the bioanalytical methods described below. The fraction unbound (\% unbound), fraction bound (\% bound) and percent device recovery were calculated in the binding assay with the following equations:

$$
\begin{aligned}
\% \text { Unbound } & =C_{\text {receiver }} \div C_{\text {donor }} \times 100 \\
\% \text { Bound } & =100-\% \text { Unbound } \\
\% \text { Device recovery } & =\left[C_{\text {receiver }}+C_{\text {donor }}\right] \div C_{\text {final }} \times 100
\end{aligned}
$$

The percent device recovery in all strains was $>95 \%$, except for $(+)-(R)$ VER in Göttingen plasma for which recovery was $88 \%$.

\section{Bioanalysis}

MET and VER $((+)-(R)$-VER, $(-)-(S)$-VER, $(+)-(R)-$ NOR or $(-)-(S)$-NOR, modified method [22] plasma concentrations were determined with an LC/MS/MS assay at Quintiles Biosciences (IN, USA). The internal standard $\left[{ }^{2} \mathrm{H}_{6}\right]$ MET in $180 \mu \mathrm{l}$ of acetonitrile/ formic acid $(95: 5, \mathrm{v} / \mathrm{v})$ was added to plasma samples $(25 \mu \mathrm{l})$, mixed and centrifuged. The resulting supernatants were diluted tenfold with acetonitrile/formic acid (95:5, v/v) and subjected to LC/MS/MS analysis. Chromatography was performed using a Betasil Silica-100 column $2.1 \times 50 \mathrm{~mm} 5 \mu \mathrm{m}$ HPLC column (Thermo Scientific, MA, USA), with a gradient elution using mobile phases $A$ : water/formic acid/1M $\mathrm{NH}_{4} \mathrm{HCO}_{3},(1000: 2: 2, \mathrm{v} / \mathrm{v})$ and $\mathrm{B}$ : acetonitrile/ water/formic acid/1M NH $\mathrm{NHCO}_{3}, \quad(1000: 25: 2: 2$, $\mathrm{v} / \mathrm{v})$. Mass spectrometric detection was performed with a mass spectrometer equipped with a turbo ion spray source (API 4000, Applied Biosystems, CA, USA), using selected reaction monitoring in positive ion mode ( $\mathrm{m} / \mathrm{z}$ transitions of $130.1>71.1$ for MET and 136.1 $>77.1$ for the internal standard). For $(+)-(R)$-VER, $(-)-(S)$-VER, $(+)-(R)$-NOR or $(-)-(S)$ NOR analyses, a $25 \mu \mathrm{l}$ aliquot of each plasma sample, standard or quality control was mixed with $25 \mu \mathrm{l}$ of 
internal standard solution $(50 \mathrm{ng} / \mathrm{ml}$ D7-R or S-VER and D7-R or S-NOR), $10 \mu \mathrm{l}$ of $2 \mathrm{~N} \mathrm{NaOH}$ and 500 $\mu \mathrm{l}$ of hexane, then centrifuged to separate the two liquid layers. A $425 \mu \mathrm{l}$ volume of each sample's upper layer was transferred to a new 96-well plate and evaporated to dryness. The extracts were reconstituted with $100 \mu \mathrm{l}$ of 90:5:5:0.1 heptane/isopropanol/ ethanol/diethylamine and analyzed by LC-MS/MS using a CHIRALPAK AD-RH (Daicel) $150 \times 4.6$ $\mathrm{mm} 5 \mu \mathrm{m}$ column and a mobile phase of 90:5:5:0.1 hexanes/isopropanol/ethanol/diethylamine delivered at $2 \mathrm{ml} / \mathrm{min}$ with $0.3 \mathrm{ml} / \mathrm{min}$ of acetonitrile added postcolumn to improve sensitivity. Calibration curves were prepared in matrix from 1 to $5000 \mathrm{ng} / \mathrm{ml}$. SRM transitions (positive ion mode) with precursor and product ions for each analyte and internal standard were acquired with an Applied Biosystems/MDS Sciex API4000 tuned to achieve unit resolution (0.7 $\mathrm{DA}$ at $50 \%$ full width at half maximum [FWHM]) using Analyst software (version 1.4.2).

\section{PK data analysis}

The PK parameters were determined using noncompartmental analysis from Watson bioanalytical LIMS (v.7.4) from Thermo Scientific (MA, USA). Plasma concentrations of analytes below the lower limit of quantitation were reported as below quantitation limit and a value of 0 was used for determination of PK parameters and mean plasma concentrations. Plasma samples with concentrations greater than the upper limit of quantitation value were determined by dilution. The PK parameters calculated include area under the curve (AUC) of the plasma concentration versus time curve $\left(\mathrm{AUC}_{0-48 \mathrm{~h}}\right.$ ), maximum concentration reached in the plasma concentration versus time curve $\left(\mathrm{C}_{\max }\right)$, time to reach the maximum concentration $\left(\mathrm{t}_{\max }\right)$ and the relative oral bioavailability $(\mathrm{F})$ defined as the dose-adjusted ratio of $\mathrm{AUC}_{0-48 \mathrm{~h}}$ after oral administration to $\mathrm{AUC}_{0-48 \mathrm{~h}}$ after intravenous administration. Additionally, plasma clearance $\left(\mathrm{CL}_{\mathrm{p}}\right)$ and elimination half-life $\left(\mathrm{t}_{1 / 2}\right)$ were determined with concentration time data after intravenous administration. The mean, standard deviation and the CV were reported for these data.

\section{Statistical analysis}

The means and SDs of the PK parameters are reported along with their CVs to illustrate the relative interanimal differences. Statistical comparisons of PK parameters were evaluated for all strains. Multiple group statistical analyses were used to compare strain differences using the JMP ${ }^{\circledR}$ Statistical Software from the SAS Institute (NC, USA).

\section{Results \& discussion}

The two drugs tested in this investigation were selected as they represent two different clearance mechanisms; MET, a low protein bound compound, is primarily cleared renally and R,S-VER, a highly protein bound compound that is mainly cleared by hepatic metabolism.

\section{Pharmacokinetics of MET}

We have demonstrated that the plasma concentration versus time profiles for MET when delivered by both oral or intravenous administration were similar across strains, with the exception of the intravenous profile in Göttingens (Figure 1). Based on the oral and intravenous PK profiles of MET, early distribution was faster in the Göttingen strain compared with the other three strains (Figure 1). Upon intravenous administration, plasma MET concentrations declined rapidly and were below level of quantitation (BQL $=1 \mathrm{ng} / \mathrm{ml}$ ) after $8 \mathrm{~h}$ in the Göttingen and $10 \mathrm{~h}$ in the Yucatan strain, so that terminal elimination half-life values could not be determined for these two strains. With noncompartmental PK analysis, the plasma clearance $\left(\mathrm{Cl}_{\mathrm{p}}\right)$ parameter was significantly higher in the Göttingen strain $(19.6 \pm 2.5$ $\mathrm{ml} / \mathrm{min} / \mathrm{kg}$ ) than in other strains (ranging from 8.7 to $10.1 \mathrm{ml} / \mathrm{min} / \mathrm{kg}$ ), (Oneway ANOVA: $\mathrm{F}(3,11)$ ratio $=31.3, \mathrm{p}<0.0001$, with $\mathrm{p}<0.0001$ Dunnett's tests) (Figure 2A). Based on the assumption that unbound drug drives clearance, and given that MET is negligibly bound to plasma proteins, the unbound plasma clearance can be compared with glomerular filtration rate (GFR) in minipig versus humans. In humans, GFR is reported to be $1.8 \mathrm{ml} / \mathrm{min} / \mathrm{kg}$ [7] and in pigs, it is reported to be $4.7 \mathrm{ml} / \mathrm{min} / \mathrm{kg}$ [23,24]. Assuming similar protein binding and clearance across human and the four minipig strains, the ratio of unbound clearance to GFR is greater than 2, and indicative of active renal secretion (Table 2) for MET. In comparison to other minipig strains, this ratio was most similar between human and Göttingens, suggesting that intravenous $\mathrm{PK}$ in this strain may be more closely predictive of human clearance for renally eliminated drugs. In humans, MET is transported by a renal basolateral organic cation transporter (hOCT2 or SLC22A2) [25]. The expression of the cation transporter, slc22a1 has been demonstrated in freshly isolated proximal tubular cells from pig kidneys [26], although the activity of this transporter in the pig is unknown. Furthermore, strain differences in the expression of this transporter have not been studied. Whether higher expression and functional activity of slc22a1 in Göttingens versus other strains have an impact on MET clearance differences is unknown at this time and worth evaluating. Upon oral administration, MET was rapidly absorbed with a $\mathrm{T}_{\max }$ between 1 and $2 \mathrm{~h}$ and the overall $\mathrm{C}_{\max }$ and 

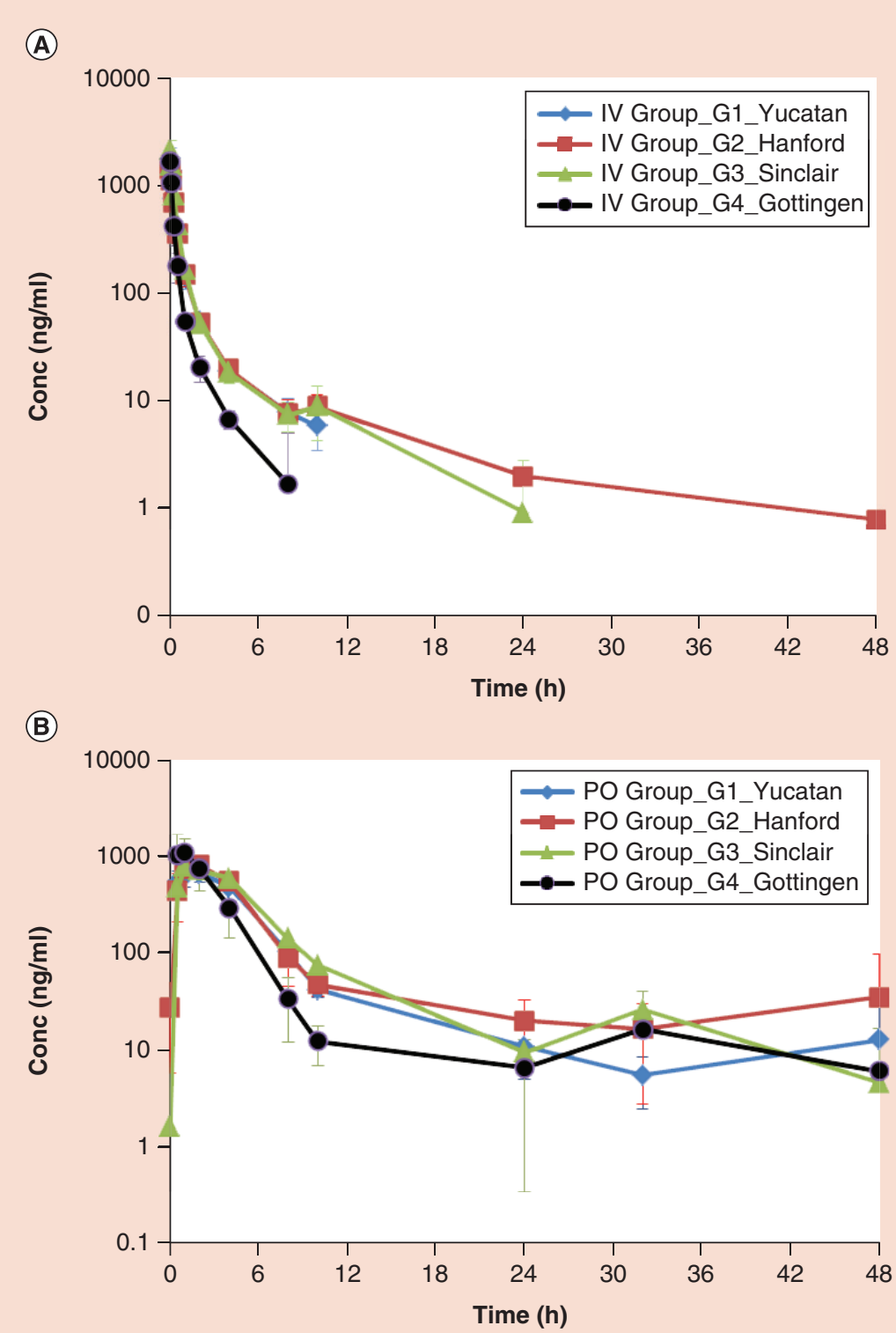

Figure 1. Mean ( $\pm S D, n=4 ; n=3$ for Göttingen) metformin plasma concentration-time profiles. Data shown following a $0.5 \mathrm{mg} / \mathrm{kg}$ intravenous dose (A) or $5 \mathrm{mg} / \mathrm{kg}$ oral dose (B) administration to fasted Yucatan (blue diamond), Hanford (red square), Sinclair (green triangle) or Göttingen (black circle) minipig.

AUC $_{0-24 \mathrm{~h}}$ values were not significantly different among the four strains as shown in Figure 2B. The elimination half-life after oral administration was generally similar among all strains (ranging from approximately 8 to $12 \mathrm{~h}$ ), except the Göttingen. A comparison with the Göttingen could not be performed as the elimination profile could not be fitted with the PK model in two of the three animals, though the half-life in one animal was short (1.3 h, data not shown). The oral bioavailability of MET in humans is between 40 and 60\% [17] and is similar to the range (48-56\%) obtained in three of the minipig strains, but appeared to be higher in the Göttingen strain (89\%, see Supplementary Data).
The high oral bioavailability in Göttingens is likely high due to the abbreviated AUC with a time interval of only $8 \mathrm{~h}$ after intravenous dosing compared with a 48-h interval with the oral profile and may not accurately represent oral bioavailability in this study. While the unbound clearance relative to GFR appears to be most similar between human and Göttingens compared with the other strains, the overall oral bioavailability is similar between human and the other strains.

\section{Pharmacokinetics of (+)-(R)-VER \& (-)-(S)-VER}

Upon intravenous administration of $S$, R-VER to four minipig strains, the plasma concentration versus 


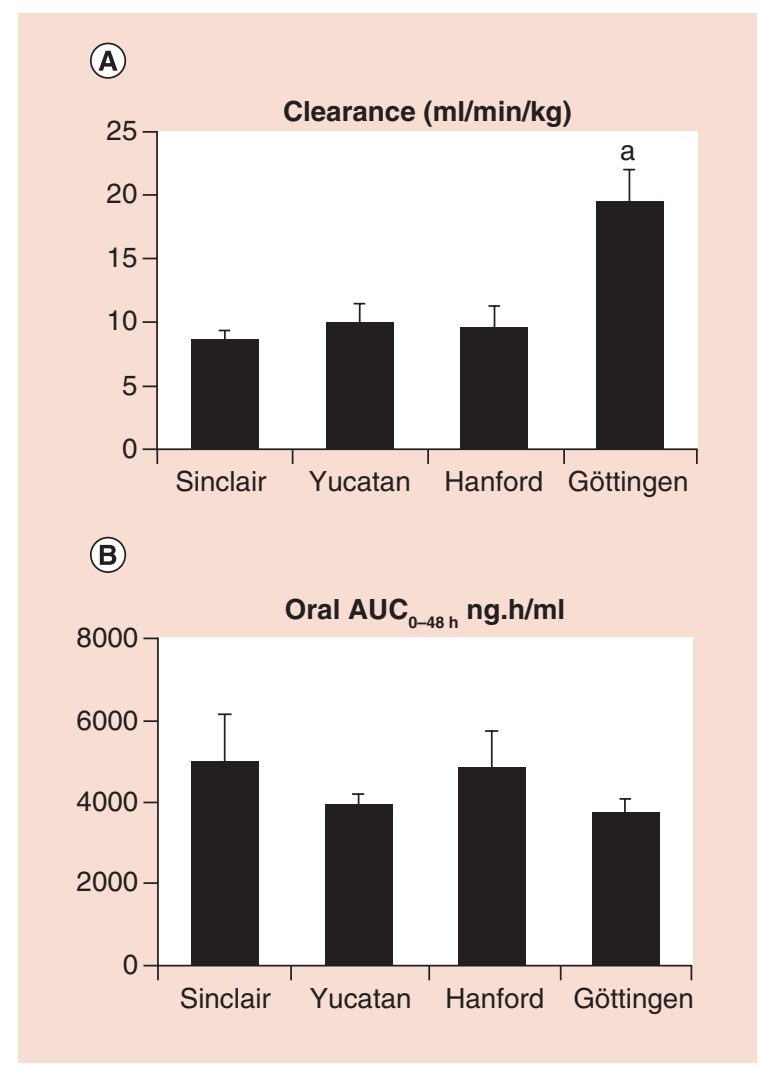

Figure 2. Comparison of mean ( $\pm S D, n=4 ; n=3$ for Göttingen) pharmacokinetics parameters. Intravenous $\mathrm{Clp}(\mathrm{A})$ or oral $\mathrm{AUC}_{0-48 \mathrm{~h}}(\mathrm{~B})$ in various strains of minipig. ${ }^{a} \mathrm{Clp}$ in Göttingen compared with other strains, $p<0.0001$, Dunnett's test.

time profiles of both enantiomers, $(+)-(R)$-VER and $(-)-(S)$-VER were superimposable and indicative of no strain differences (Figure 3). This is different from what has been reported in humans and rats, where the exposure of $(+)-(R)$-VER is higher than $(-)-(S)-$ VER in humans and opposite in rats. In humans, $(-)-(S)-V E R$ is metabolized to a greater extent more actively than the $(+)-(R)$-VER resulting in a 2.5 -fold higher bioavailability of the $(+)-(R)$ - versus $(-)-(S)$ enantiomer [27]. The only difference observed was in the overall plasma clearances of $(+)-(R)$-VER and $(-)-(S)-V E R$, which were significantly lower in the Sinclair strain (Oneway ANOVA: $\mathrm{F}(3,11)$ ratio $=$ 4.72, $\mathrm{p}=0.023$, with $\mathrm{p}<0.05$ Dunnett's tests and Oneway ANOVA: $\mathrm{F}(3,11)$ ratio $=4.85, \mathrm{p}=0.021$, with $\mathrm{p}<0.05$ Dunnett's tests; respectively) compared with that in the other three strains (Figure 4). After oral administration, the $\mathrm{AUC}_{0-48 \mathrm{~h}}, \mathrm{C}_{\max }$ and $\mathrm{T}_{\max }$ values for both enantiomers were similar across all strains (Supplementary Table 2). The oral bioavailability of $(+)-(R)$-VER and $(-)-(S)$-VER was low and similar across all strains and enantioselectivity was not observed in any of the strains, a finding that contrasted with previously reported rat and human data [20]. The exposure of the active N-demethylation metabolites, $(+)-(R)-\mathrm{NOR}$ and $(-)-(S)$-NOR was also determined in this study as this metabolite represents one of the two major products of R,SVER metabolism [19]. The plasma concentrations of the N-demethylated metabolites, $(+)-(R)$-NOR and $(-)-(S)$-NOR were negligible after intravenous dosing (data not shown). As shown in Figure $4 \mathrm{~B}$, the oral $\mathrm{AUC}_{0-48 \mathrm{~h}}$ ratio of $(+)-(R)-\mathrm{NOR} /(+)-(R)$-VER was consistently higher than that of $(-)-(S)$-NOR / $(-)-(S)-V E R$ in all four strains of minipig. This indicated that in the minipig, there may be a preferential conversion of $(+)-(R)$-VER to $(+)-(R)$-NOR over $(-)-(S)$-VER to $(-)-(S)$-NOR. Whether this is due to stereoselective differences in the initial conversion of VER to NOR or further dispositional differences of the metabolites is not known.

\section{Human \& porcine cytochromes \& metabolism of verapamil}

Different CYP isoforms are present in different animal species, although there is homology among species [28]. Since the sequences do vary between species, some activity differences are expected between species as well as human and pigs [11,29]. Soucek et al. [30] reported that minipig cytochrome P450 3A, 2A

\begin{tabular}{|c|c|c|c|}
\hline Species or minipig strain & GFR (ml/min//kg) & MET Clp (ml/min//kg) & Unbound Clp/GFR ratio $\$$ \\
\hline Human $^{\dagger}$ & 1.8 & 6.4 & 3.6 \\
\hline Yucatan $^{\ddagger}$ & 4.7 & 10.1 & 2.2 \\
\hline Hanford ${ }^{\ddagger}$ & 4.7 & 9.7 & 2.1 \\
\hline Sinclair ${ }^{\ddagger}$ & 4.7 & 8.7 & 1.9 \\
\hline Göttingen ${ }^{\ddagger}$ & 4.7 & 19.6 & 4.2 \\
\hline
\end{tabular}



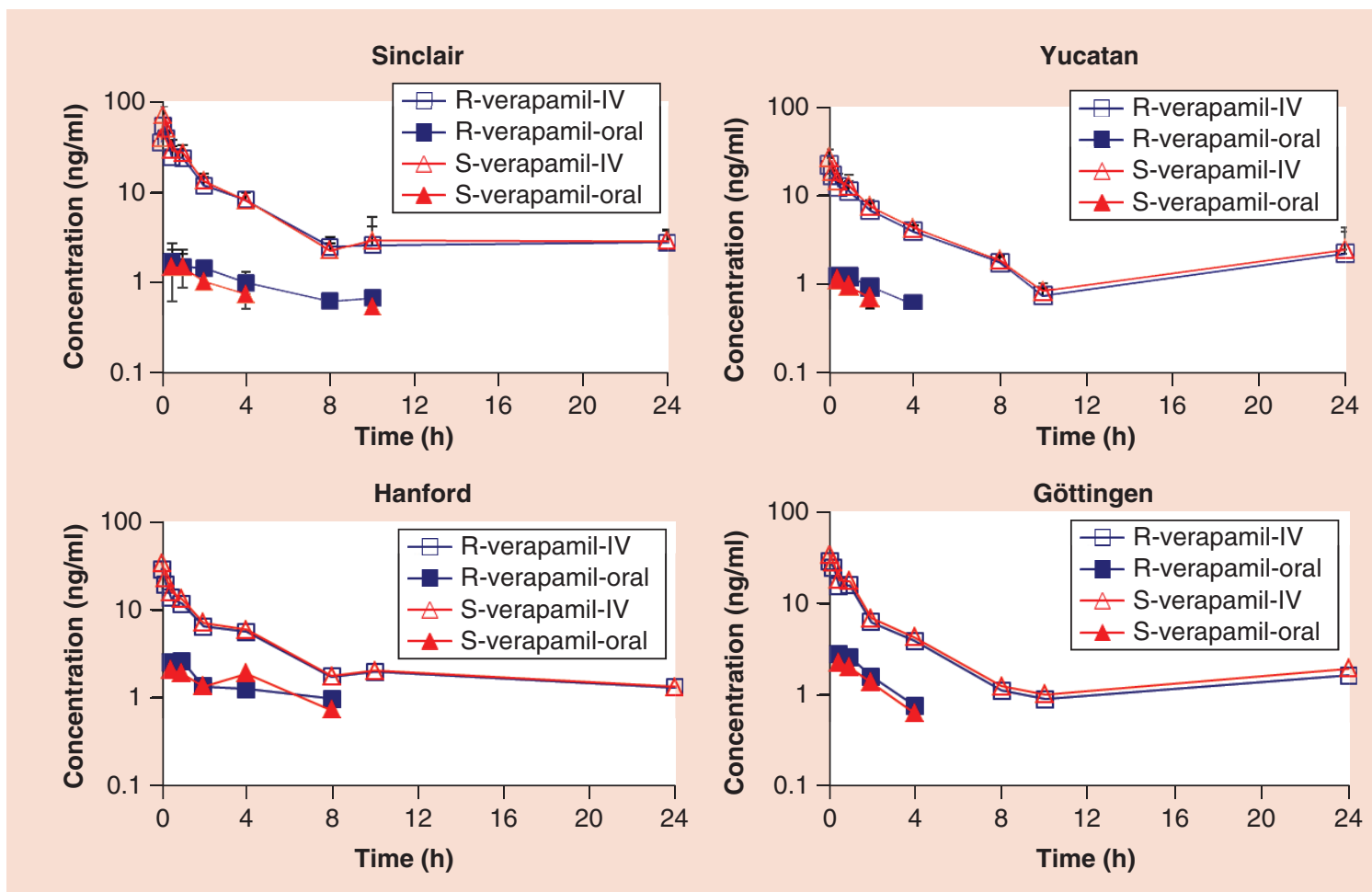

Figure 3. Mean (+)-(R)-VER (square symbols) or (-)-(S)-VER (triangle symbols) plasma concentration $( \pm \mathrm{SD}, \mathrm{n}=$ $4 ; \mathrm{n}=3$ for Göttingen)-time profiles following a $0.2 \mathrm{mg} / \mathrm{kg}$ intravenous (open symbols) or $2 \mathrm{mg} / \mathrm{kg}$ oral (closed symbols) dose of R,S-VER to fasted Yucatan, Hanford, Sinclair or Göttingen minipig.

and $2 \mathrm{C}$ enzymes have similar properties to human analogs. There are similarities but also some differences between pig and human cytochrome P450 enzymes [31]. Skaanild [11] has summarized the pig liver cytochrome P450 enzyme likeness and dissimilarities to human. The isozymes with similarity to human counterparts are identical in about $75 \%$ of their cDNA sequence. Tracy et al. [19] indicated that the enantiomers of VER and NOR are metabolized by CYP450 3A4, 3A5 and 2C8 in human. The CYP3 family is the most important drug metabolizing family and metabolizes approximately $34 \%$ of compounds and represents $30-40 \%$ of total CYP in the human liver [32] and 14\% of total CYP in pigs [33]. Using VER as a substrate, Thorn et al. [34] have demonstrated that CYP3A4 activity is comparable in pig versus human. There are differences in transcriptional regulation of CYP3A between humans and pigs, and while tissue expression patterns are similar interindividual variances have been detected. Yucatan pigs have higher activity of CYP3A compared with Göttingen and conventional pigs $[12,13]$. Porcine CYP2C33v4 has only $62.6 \%$ homology to human CYP2C9 [33]. Porcine CYP2C enzymes show some cross reactivity toward many human test substrates, but not those specific for human CYP2C, making extrapolation between pigs and humans for CYP2C difficult $[11,14]$.
Protein binding of $(+)-(R)$-VER \& (-)-(S)-VER

In humans, the clearance and protein binding of VER is known to be enantioselective (the clearance of $(+)-(S)$-VER is greater than that of $(-)-(R)$-VER and protein binding of $(+)-(R)-\mathrm{VER}$ is greater than that of $(-)-(S)$-VER) and opposite to that in the rat [20]. We examined the protein binding of each of the enantiomers of VER in plasma from various minipig strains and compared with human plasma. We found moderate plasma protein binding in Göttingen, Hanford and Yucatan minipig (68.9-80.3\%) that was somewhat lower than human plasma (80.0-87.4\%). Lowest plasma protein binding was observed in the Yucatan strain (68.9-70.9\%). On average, the protein binding of VER in human plasma (80-9-87.4\%) was most similar to Sinclair plasma (82.5-85.4\%). In terms of enantioselectivity, less protein binding was observed with $(-)-(S)$-VER $(80.9 \%)$ than for $(+)-(R)$-VER $(87.4 \%)$ in human plasma, whereas plasma binding in all minipig strains was opposite; higher binding for $(-)-(S)$ VER than $(+)-(R)$-VER (Table 3$)$. This enantiomeric selectivity in minipig plasma protein binding did not appear to influence the overall plasma clearance of the enantiomers (Figure 4), however preferential conversion of R,S-VER to $(+)-(R)$-NOR over $(-)-(S)$-NOR (Figure $4 \mathrm{~B}$ ) in minipig may be driven by stereo-selectivity of plasma protein binding to some extent. The 


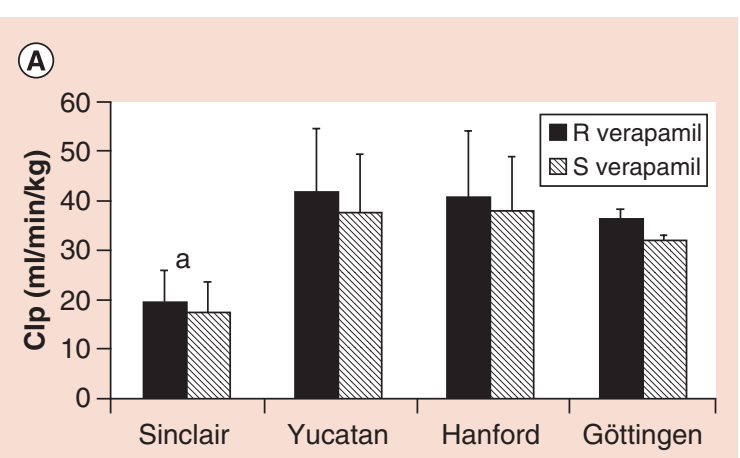

(B)

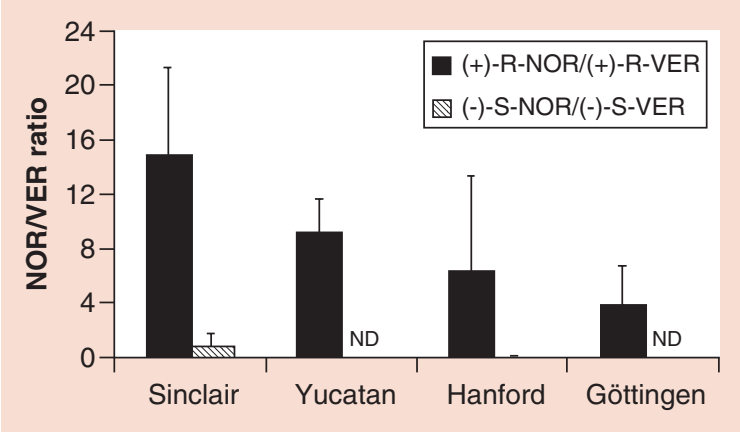

Figure 4. Comparison of mean $( \pm S D, n=$ 4; $\mathbf{n}=\mathbf{3}$ for Göttingen) pharmacokinetics parameters. (A) Comparison of mean plasma clearance of $(+)-(R)$-VER and (-)-(S)-VER across four strains of minipig after intravenous administration of $R, S-V E R$

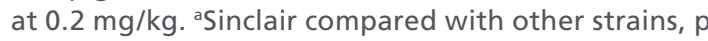
$<0.05$, Dunnett's test, $n=4$. (B) Comparison of mean $\mathrm{AUC}_{0-48 \mathrm{~h}}$ ratio of (+)-(R)-NOR or (-)-(S)-NOR to their respective parent enantiomers after oral administration of $R, S-V E R$ at $2 \mathrm{mg} / \mathrm{kg}$ in various minipig strains.

observations as summarized in Table 4 indicate that enantioselective disposition of $(+)-(R)$ versus $(-)-(S)$ VER is different and opposite between human, rat and minipig strains. Although it is premature to extend this conclusion to all racemic drugs, this may indicate that minipigs may exhibit specific enantioselective patterns. For example, although the absorption of ketoprofen is not stereoselective in human and rats [35,36], there is enantioselective clearance swine [37]. In addition, large variation in the metabolism and elimination of the enantiomeric o,p'-DDD with interanimal opposite enantiomeric profiles has been observed in Göttingen minipigs [38].

\section{Conclusion}

We have demonstrated some strain differences in the PK and disposition of drugs that are cleared by the kidney or metabolized by the liver in minipig. While renal clearance generally appeared to be similar across strains, the Göttingen appeared to clear MET more similarly to human than other strains. As for R,S-VER, there were no strain differences in the overall PK and disposition of its enantiomers. However, the enantioselective disposition in minipig was different from both rat and human. These data indicate that consideration of the impact of liver metabolism and dispositional differences in minipig strains is important when selecting the relevant strain for PK studies that may be used for human PK predictions.

\section{Future perspective}

The use of the minipig as an alternate species for the pharmacological and toxicological evaluation of human drugs has been growing over the past 10 years. Unlike other nonrodent species that are used in biomedical research, multiple strains of minipigs are available and although they share a common genetic heritage, phenotypic differences can be expected. Because

\begin{tabular}{|c|c|c|c|}
\hline Plasma $^{\dagger}$ species, strain & Enantiomer & $\%$ Unbound $(\text { mean } \pm S D)^{\ddagger}$ & $\%$ Bound $(\text { mean } \pm S D)^{\ddagger}$ \\
\hline \multirow{2}{*}{ Minipig Sinclair } & $(+)-(R)$ & $17.5 \pm 0.7$ & $82.5 \pm 0.7$ \\
\hline & $(-)-(S)$ & $14.6 \pm 0.4$ & $85.4 \pm 0.4$ \\
\hline \multirow[t]{2}{*}{ Minipig Yucatan } & $(+)-(R)$ & $31.1 \pm 1.4$ & $68.9 \pm 1.4$ \\
\hline & $(-)-(S)$ & $29.1 \pm 0.7$ & $70.9 \pm 0.7$ \\
\hline \multirow[t]{2}{*}{ Minipig Hanford } & $(+)-(R)$ & $21.2 \pm 0.8$ & $78.8 \pm 0.8$ \\
\hline & $(-)-(S)$ & $19.7 \pm 1.1$ & $80.3 \pm 1.1$ \\
\hline \multirow[t]{2}{*}{ Minipig Göttingen } & $(+)-(R)$ & $28.6 \pm 2.1$ & $71.4 \pm 2.1$ \\
\hline & $(-)-(S)$ & $21.0 \pm 0.8$ & $79.0 \pm 0.8$ \\
\hline \multirow[t]{2}{*}{ Human } & $(+)-(R)$ & $12.6 \pm 0.3$ & $87.4 \pm 0.3$ \\
\hline & $(-)-(S)$ & $19.1 \pm 0.5$ & $80.9 \pm 0.5$ \\
\hline
\end{tabular}


Table 4. General direction of enantioselectivity for exposure, clearance and protein binding in various species.

\begin{tabular}{|c|c|c|c|}
\hline Parameter & ${ }^{\dagger}$ Rat & ${ }^{\dagger}$ Human & Minipig \\
\hline Oral AUC & $(-)-(S)>(+)-(R)$ & $(+)-(R)>(-)-(S)$ & $(+)-(R)=(-)-(S)$ \\
\hline Clp & $(+)-(R)>(-)-(S)$ & $(-)-(S)>(+)-(R)$ & $(+)-(R)=(-)-(S)$ \\
\hline Plasma binding & $(+)-(R)>(-)-(S)$ & $(-)-(S)>(+)-(R)$ & $(+)-(R)>(-)-(S)$ \\
\hline \multicolumn{4}{|c|}{$\begin{array}{l}\text { 'Data taken from }[20,27] \text {. } \\
(-)-(S) \text {-VER is metabolized more actively than the R-form in human resulting in a } 2.5 \text {-fold higher concentration of the }(+)-(R) \text {-VER } \\
\text { enantiomer in plasma. } \\
\text { AUC: Area under the curve. }\end{array}$} \\
\hline
\end{tabular}

the genetic homogeneity found in other research animals (i.e., inbreeding) is not a good representation of the genetic variability found in human, we believe that the variability observed in minipigs will help to better model and predict human pharmacology.

\section{Acknowledgements}

The authors would like to thank S Renna for coordinating and directing the live phase of the minipig pharmacokinetic studies and F Kpakima for coordinating the protein-binding study.

Financial \& competing interests disclosure

The authors have no relevant affiliations or financial involvement with any organization or entity with a financial inter- est in or financial conflict with the subject matter or materials discussed in the manuscript. This includes employment, consultancies, honoraria, stock ownership or options, expert testimony, grants or patents received or pending, or royalties.

No writing assistance was utilized in the production of this manuscript.

\section{Ethical conduct of research}

The authors state that they have obtained appropriate institutional review board approval or have followed the principles outlined in the Declaration of Helsinki for all human or animal experimental investigations. In addition, for investigations involving human subjects, informed consent has been obtained from the participants involved.

\section{Executive summary}

\section{Aim}

- We explored the possible differences in oral and systemic pharmacokinetics of two known drugs in four strains of minipig (metformin and verapamil, a racemic mixture). In addition, the observed data were compared with published human data.

\section{Results}

- We observed differences in drug distribution, plasma clearance, oral bioavailability, enantiomeric clearance ratio and plasma protein binding. We also noted that the enantioselective disposition of the racemic drug was different in minipig than human.

\section{Conclusion}

- This work highlights the importance of considering the impact of metabolic and dispositional differences in minipig strains when conducting pharmacokinetics studies.

\section{References}

Papers of special note have been highlighted as:

- of interest; $\bullet \bullet$ of considerable interest

1 Bode G, Clausing P, Gervais F et al. The utility of the minipig as an animal model in regulatory toxicology. $J$. Pharmacol. Toxicol. Methods 62(3), 196-220 (2010).

2 Stricker-Krongrad A, Shoemake CR, Bouchard GF. The miniature swine as a model in experimental and translational medicine. Toxicol. Pathol. 44(4), 612-623 (2016).

- An overview of the pharmacological and surgical models that are available in the minipig.

3 Stricker-Krongrad A, Shoemake CR, Pereira ME, Gad SC, Brocksmith D, Bouchard GF. Miniature swine breeds in toxicology and drug safety assessments: what to expect during clinical and pathology evaluations. Toxicol. Pathol. 44(3), 421-427 (2016).

4 Simmons MN, Subramanian V, Crouzet $S$ et al. Alphamelanocyte stimulating hormone analogue AP214 protects against ischemia induced acute kidney injury in a porcine surgical model. J. Urol. 183(4), 1625-1629 (2010).

5 Tao Z, Chen B, Tan X et al. Coexpression of VEGF and angiopoietin-1 promotes angiogenesis and cardiomyocyte proliferation reduces apoptosis in porcine myocardial infarction (MI) heart. Proc. Natl Acad. Sci. USA 108(5), 2064-2069 (2011).

6 Timmers L, Henriques JP, De Kleijn DP et al. Exenatide reduces infarct size and improves cardiac function in a porcine model of ischemia and reperfusion injury. J. Am. Coll. Cardiol. 53(6), 501-510 (2009). 
7 Davies B, Morris T. Physiological parameters in laboratory animals and humans. Pharm. Res. 10 (7), 1093-1095 (1993).

8 Kararli TT. Comparison of the gastrointestinal anatomy, physiology, and biochemistry of humans and commonly used laboratory animals. Biopharm. Drug Dispos. 16(5), 351-380 (1995).

9 Suenderhauf C, Parrott N. A physiologically based pharmacokinetic model of the minipig: data compilation and model implementation. Pharm. Res. 30(1), 1-15 (2013).

10 Helke KL, Nelson KN, Sargeant AM et al. Pigs in toxicology: breed differences in metabolism and background findings. Toxicol. Pathol. 44(4), 575-590 (2016).

-. Describes the differences in drug metabolism between the different breeds of swine and minipigs.

11 Skaanild MT. Porcine cytochrome P450 and metabolism. Curr. Pharm. Des. 12(11), 1421-1427 (2006).

12 Skaanild MT, Friis C. Characterization of the P450 system in Gottingen minipigs. Pharmacol. Toxicol. 80(Suppl. 2), 28-33 (1997).

- Complete characterization of the cytochrome P450 enzymes in Göttingen minipigs.

13 Skaanild MT, Friis C. Cytochrome P450 sex differences in minipigs and conventional pigs. Pharmacol. Toxicol. 85(4), 174-180 (1999).

14 Skaanild MT, Friis C. Porcine CYP2A polymorphisms and activity. Basic Clin. Pharmacol. Toxicol. 97(2), 115-121 (2005).

15 Suenderhauf C, Tuffin G, Lorentsen H, Grimm HP, Flament C, Parrott N. Pharmacokinetics of paracetamol in Gottingen minipigs: in vivo studies and modeling to elucidate physiological determinants of absorption. Pharm. Res. 31(10), 2696-2707 (2014).

16 Oberle RL, Das H, Wong SL, Chan KK, Sawchuk RJ. Pharmacokinetics and metabolism of diclofenac sodium in Yucatan miniature pigs. Pharm. Res. 11(5), 698-703 (1994).

17 Scheen AJ. Clinical pharmacokinetics of metformin. Clin. Pharmacokinet. 30(5), 359-371 (1996).

18 Bhatti MM, Foster RT. Pharmacokinetics of the enantiomers of verapamil after intravenous and oral administration of racemic verapamil in a rat model. Biopharm. Drug Dispos. 18(5), 387-396 (1997).

19 Tracy TS, Korzekwa KR, Gonzalez FJ, Wainer IW. Cytochrome $\mathrm{P} 450$ isoforms involved in metabolism of the enantiomers of verapamil and norverapamil. Br. J. Clin. Pharmacol. 47(5), 545-552 (1999).

20 Robinson MA, Mehvar R. Enantioselective distribution of verapamil and norverapamil into human and rat erythrocytes: the role of plasma protein binding. Biopharm. Drug Dispos. 17(7), 577-587 (1996).

21 Gad SC, Spainhour CB, Shoemake C et al. Tolerable levels of nonclinical vehicles and formulations used in studies by multiple routes in multiple species with notes on methods to improve utility. Int. J. Toxicol. 35(2), 95-178 (2016).

22 Mateus FH, Lepera JS, Marques MP, Boralli VB, Lanchote VL. Simultaneous analysis of the enantiomers of verapamil and norverapamil in rat plasma by liquid chromatography- tandem mass spectrometry. J. Pharm. Biomed. Anal. 45(5), 762-768 (2007).

23 Frennby B. Use of iohexol clearance to determine the glomerular filtration rate. A comparison between different clearance techniques in man and animal. Scand. J. Urol. Nephrol. Suppl. 182, 1-63 (1997).

24 Frennby B, Sterner G, Almen T, Chai CM, Jonsson BA, Mansson S. Clearance of iohexol, 51Cr-EDTA and endogenous creatinine for determination of glomerular filtration rate in pigs with reduced renal function: a comparison between different clearance techniques. Scand. J. Clin. Lab. Invest. 57(3), 241-252 (1997).

25 Kimura N, Masuda S, Tanihara Y et al. Metformin is a superior substrate for renal organic cation transporter OCT2 rather than hepatic OCT1. Drug Metab. Pharmacokinet. 20(5), 379-386 (2005).

26 Schlatter P, Gutmann H, Drewe J. Primary porcine proximal tubular cells as a model for transepithelial drug transport in human kidney. Eur. J. Pharm. Sci. 28(1), 141-154 (2006).

27 Vogelgesang B, Echizen H, Schmidt E, Eichelbaum M. Stereoselective first-pass metabolism of highly cleared drugs: studies of the bioavailability of $\mathrm{L}$ - and D-verapamil examined with a stable isotope technique. Br. J. Clin. Pharmacol. 58(7), S796-S803; discussion S804-S796 (2004).

28 Bogaards JJ, Bertrand M, Jackson P et al. Determining the best animal model for human cytochrome $\mathrm{P} 450$ activities: a comparison of mouse, rat, rabbit, dog, micropig, monkey and man. Xenobiotica 30(12), 1131-1152 (2000).

-• Interspecies differences in cytochrome P450 metabolism with a specific focus on translational value.

29 Dalgaard L. Comparison of minipig, dog, monkey and human drug metabolism and disposition. J. Pharmacol. Toxicol. Methods 74, 80-92 (2015).

- A good reference paper on interspecies differences in drug pharmacokinetics.

30 Soucek P, Zuber R, Anzenbacherova E, Anzenbacher P, Guengerich FP. Minipig cytochrome P450 3A, 2A and 2C enzymes have similar properties to human analogs. $B M C$ Pharmacol. 1, 11 (2001).

31 Anzenbacher P, Anzerbacherova E, Zuber R, Soucek P, Guengerich F. Pig and minipig cytochromes P450. Drug Metab. Dispos. 30 (1), 100-102 (2002).

32 Omiecinski CJ, Remmel RP, Hosagrahara VP. Concise review of the cytochrome P450s and their roles in toxicology. Toxicol. Sci. 48(2), 151-156 (1999).

33 Achour B, Barber J, Rostami-Hodjegan A. Cytochrome P450 pig liver pie: determination of individual cytochrome P450 isoform contents in microsomes from two pig livers using liquid chromatography in conjunction with mass spectrometry [corrected]. Drug Metab. Dispos. 39(11), 2130-2134 (2011).

34 Thorn HA, Lundahl A, Schrickx JA, Dickinson PA, Lennernas H. Drug metabolism of CYP3A4, CYP2C9 and CYP2D6 substrates in pigs and humans. Eur. J. Pharm. Sci. 43(3), 89-98 (2011).

35 Foster RT, Jamali F. Stereoselective pharmacokinetics of ketoprofen in the rat. Influence of route of administration. 
Drug Metab. Dispos. 16(4), 623-626 (1988).

36 Foster RT, Jamali F, Russell AS, Alballa SR.

Pharmacokinetics of ketoprofen enantiomers in young and elderly arthritic patients following single and multiple doses. J. Pharm. Sci. 77(3), 191-195 (1988).

37 Mustonen K, Niemi A, Raekallio M et al. Enantiospecific ketoprofen concentrations in plasma after oral and intramuscular administration in growing pigs. Acta Vet. Scand. 54, 55 (2012).
38 Cantillana T, Lindstrom V, Eriksson L, Brandt I, Bergman A. Interindividual differences in o,p'-DDD enantiomer kinetics examined in Gottingen minipigs. Chemosphere 76(2), 167-172 (2009).

39 Pantikainin PJ. Comparison of solution, rapidly dissolving tablet, and three sustained release products. Int. J. Clin. Pharmacol. Ther. Tox. 24(4), 231-220 (1986). 
